\begin{tabular}{|c|l|}
\hline Title & $\begin{array}{l}\text { Graphene oxide captured for green use: Influence on the structures of cal cium alginate and macroporous alginic beads } \\
\text { and their application to aqueous removal of acridine orange }\end{array}$ \\
\hline Author(s) & Sun, Ling; Fugetsu, Bunshi \\
\hline Citation & $\begin{array}{l}\text { Chemical Engineering Journal, 240,565-573 } \\
\text { https://doi.org/10.1016/.Cej.2013.10.083 }\end{array}$ \\
\hline Issue Date & 201403-15 \\
\hline Doc URL & http:/hdl.handle.net/2115/54520 \\
\hline Type & article (author version) \\
\hline File Information & SUNling_CEJ.pdf \\
\hline
\end{tabular}

Instructions for use 


\section{Accepted Manuscript}

Graphene oxide captured for green use: Influence on the structures of calcium alginate and macroporous alginic beads and their application to aqueous removal of acridine orange

Ling Sun, Bunshi Fugetsu

PII: S1385-8947(13)01412-5

DOI: http://dx.doi.org/10.1016/j.cej.2013.10.083

Reference: CEJ 11422

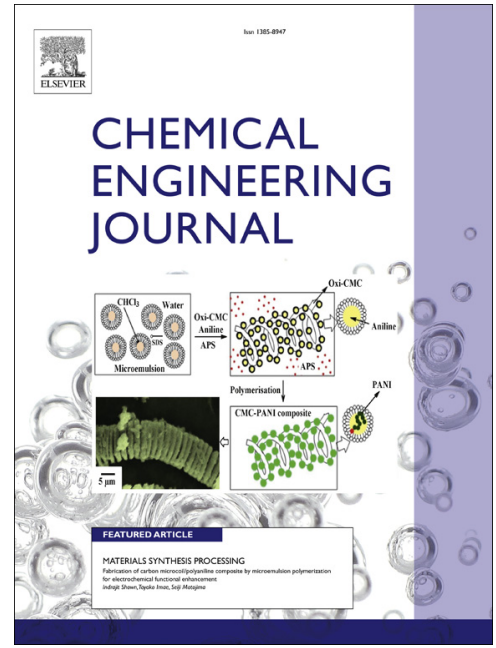

To appear in:

Chemical Engineering Journal

Received Date:

20 August 2013

Revised Date: 25 October 2013

Accepted Date:

28 October 2013

Please cite this article as: L. Sun, B. Fugetsu, Graphene oxide captured for green use: Influence on the structures of calcium alginate and macroporous alginic beads and their application to aqueous removal of acridine orange, Chemical Engineering Journal (2013), doi: http://dx.doi.org/10.1016/j.cej.2013.10.083

This is a PDF file of an unedited manuscript that has been accepted for publication. As a service to our customers we are providing this early version of the manuscript. The manuscript will undergo copyediting, typesetting, and review of the resulting proof before it is published in its final form. Please note that during the production process errors may be discovered which could affect the content, and all legal disclaimers that apply to the journal pertain. 


\title{
Graphene oxide captured for green use: Influence on the structures of calcium alginate and macroporous alginic beads and their application to aqueous removal of acridine orange
}

\section{Ling Sun*, Bunshi Fugetsu}

Division of Frontier Research, Research Department, Creative Research Institution, Hokkaido University, Sapporo 001-0021, Japan

Graduate School of Environmental Science, Hokkaido University, Sapporo 060-0810, Japan

${ }^{*}$ Corresponding author. Telephone/fax: +81-11-706-9235. E-mail: captainsun@ees.hokudai.ac.jp

\begin{abstract}
To investigate the influence of immobilized graphene oxide (GO) on host structures, it was incorporated into calcium alginate and macroporous alginic beads, and acridine orange (AO) was used as a typical dye pollutant to eliminate. Characterizations demonstrated GO was well encapsulated and had promoted both beads more porous yet to a varying extent. Kinetics studies exhibited the addition of GO resulted in adsorptions with shorter equilibrium time and faster initial adsorption rate, and the adsorbents with higher equilibrium capacities. Isotherm studies indicated the hybrid absorbents following Langmuir-type adsorptive behavior had higher maximum adsorption capacities than those without GO. In addition, GO would contribute dominantly to the removal of AO under highly acidic condition whereas alginate/alginic part became failure.
\end{abstract}

\section{Keywords}

GO, Alginate beads, Acridine orange, Porous structure 


\section{Introduction}

Increasing porosity is admittedly a critical factor influencing the absorbent performance. To form stable 3D porous gel absorbents, a conventional method is using the abundant seaweeds- and bacteria-derived alginate, a heteropolysaccharide composed of $\beta$-D-mannuronic acid and $\alpha$-L-guluronic acid, of which the molecular chains rich in hydroxyl and carboxyl groups. It is therefore easily cross-linked by various multivalent cations, such as $\mathrm{Ba}^{2+}, \mathrm{Ca}^{2+}$, and $\mathrm{Fe}^{3+}$. In the past few years, this feature as well as its biosafety, easy processing and high adsorptive selectivity, has been extensively applied to the aqueous decontamination of various metal ions [1-3], dyes [4, 5]. It is noteworthy that these absorbents could possess more unique properties with immobilizing guest materials. For instance, active carbon-entrapped calcium alginate beads showed the selectivity of removal towards positively charged methylene blue and neutral $p$-chlorophenol, while the ferric alginate mostly adsorbed negatively charged humic acid [6]. And carbon nanotube-encapsulating biocompatible barium alginate had an affinity-based selectivity among the ionic dyes of acridine orange, ethidium bromide, eosin bluish, and orange G [7]. However, in regard to the low porosity, measures are much desired to promote alginate more porous with the purpose of allowing substance diffusions into the interior structure and thus enhancing the sorption kinetics properties [8].

Graphene oxide (GO) in nature inherits the 2D carbon backbone from graphene. It has large surface area with random distributed hydroxyl, epoxy, ketone, carboxyl groups at edges and basal planes. Thereby a series of covalent and non-covalent interactions enable GO to bridge with kinds of external ions, molecules or even bulk materials, such as pi-pi stacking, hydrogen bonding, and cation-pi bonding. Thus it is highly available not only for direct decontamination, like removing $\mathrm{Cd}^{2+}, \mathrm{Co}^{2+}$, and $\mathrm{Pb}^{2+}[9,10]$, tetracycline antibiotics [11], acridine orange ( $\mathrm{AO}, \sim 3.3 \mathrm{~g} \mathrm{~g}^{-1}$ ) [12], etc., but also to prepare novel composites/hybrids as supporter, immobilizer, etc., such as GO-composited magnetic chitosan to adsorb methylene blue [13]. Both alginate and GO are highly water dispersible, resulting from the functional group ionization as well as the resultant negatively charged property; mixing them together is also available to get homogeneous solution, owing to mutual electrostatic repulsion and the hydrogen bonding. Importantly, involving GO may carry an effect to promote the hybrid composite with high porosity [14]. In addition, regarding to the GO's bio-hazardousness incompletely unveiled $[15,16]$, it demonstrated 
structures of alginate-based adsorbents, namely, calcium alginate and macroporous alginic beads. The subsequent impact on removal of $\mathrm{AO}$ from water was then demonstrated as an example in terms of time and concentration dependences. In the meantime, the adsorptive kinetics, isothermal behavior and mechanism were also discussed.

\section{Experimental}

\subsection{Materials and reagents}

Graphite (Commercial code: EC1000, average particle size $15 \mu \mathrm{m}$ as manufactured) was purchased from Ito Kokuen Co., Ltd, Mieken, Japan. Unless specifically noted, other chemicals, such as sodium alginate $\left(500 \sim 600 \mathrm{mPa} \cdot \mathrm{s}\right.$ at $10 \mathrm{~g} \mathrm{~L}^{-1}$ at $293 \mathrm{~K}$ as marked), calcium carbonate, and calcium chloride were obtained from Wako Pure Chemical Industries, Ltd., or Sigma-Aldrich Inc., Japan.

\subsection{Preparation of GO-encapsulating alginate beads}

Sodium alginate of $2 \mathrm{wt} \%$ was prepared by dissolving it into deionized water. GO of $0.10 \mathrm{wt} \%$ was prepared from the graphite using a developed Hummers-Offeman method by our group [17].

Calcium alginate beads were prepared by the conventional $\mathrm{CaCl}_{2}$-hardening method [7]. To prepare GO-encapsulating alginate beads (denoted as SA-GO-N), GO solution (50 g), sodium alginate solution (250 g) (mass ratio: GO/alginate $\sim 1 / 100$ ) was firstly mixed to be homogeneous. Then it was dropwise dripped into a magnetically stirred $\mathrm{CaCl}_{2}$ solution (about $6 \mathrm{wt} \%$ ) by virtue of a self-made apparatus comprising a 500-mL container, and an air pump with an airflow controller under a certain internal pressure. After gelation and maturation, the beads were rinsed with deionized water several times using a 100- $\mu \mathrm{m}$ mesh sieve. As compared, the beads without GO were prepared, denoted with Pure SA-N.

To prepare macroporous alginic beads, $\mathrm{HCl}(5 \mathrm{wt} \%)$ replaced $\mathrm{CaCl}_{2}$ to harden the alginate. Commercial calcium carbonate was ball-milling ground ahead for $48 \mathrm{~h}$ to decrease the particle size. Then GO solution $(50 \mathrm{~g}), \mathrm{CaCO}_{3}(2.5 \mathrm{~g})$ and sodium alginate $(250 \mathrm{~g})$ (mass ratio: $\mathrm{GO} / \mathrm{CaCO}_{3} /$ alginate $\sim 1 / 50 / 100$ ) were mixed in sequence and stirred vigorously. Next, alginic beads were prepared similarly by the above-mentioned wet process. During such, the reaction between $\mathrm{CaCO}_{3}$ and $\mathrm{HCl}$ in-situ produced a lot of $\mathrm{CO}_{2}$ gas, what accumulated inside (initially the beads floated at water surface) and further expanded the inner pores, of which the walls became much thinner. These beads were marked as 


\section{ACCEPTED MANUSCRIPT}

SA-GO-M. For comparison, the beads without GO (Pure SA-M) were also prepared. All beads were preserved in a fridge $\left(4^{\circ} \mathrm{C}\right)$. The weight was obtained by averaging over 60 air-dried beads in a $353 \mathrm{~K}$ oven.

\subsection{Batch experiments}

Time/concentration-dependent adsorptions were performed at room temperature (293 $\pm 2 \mathrm{~K})$. Beads (6 mg) were mixed with AO $\left(50 \mathrm{~mL}, 20 \mathrm{mg} \mathrm{L}^{-1}\right)$ and suffered shaking $(300 \mathrm{rpm})$ until being the equilibrium. Concentrations of AO were determined by using a UV-Vis spectrometer (JASCO V-570 spectrophotometer). Each experiment above set in triplicate for determination.

The adsorption capacity $\left(q_{t}, \mathrm{~g} \mathrm{~g}^{-1}\right)$ was calculated by the equation:

$$
q_{t}=\frac{V \times\left(C_{0}-C_{t}\right)}{m}
$$

where $V$, is the volume of the suspension $(\mathrm{mL}) ; m$, is the dry weight of beads used in the system $(\mathrm{g})$; $C_{0}$, and $C_{t}$, mean the concentrations at the initial and at each interval $\left(\mathrm{g} \mathrm{L}^{-1}\right)$. When the adsorption becomes equilibrated, we obtained the equilibrium concentration $C_{e}$, and subsequently the equilibrium capacity $q_{e}$

\subsection{Material characterization}

The characterizations involved Atomic force microscopy (AFM, Agilent series 5500 AFM instrument in tapping mode at a scanning rate of $0.5 \mathrm{~Hz}$ ), Fourier transform infrared spectroscopy (FTIR, FT/IR-6100 Spectrometer, JASCO), Scanning electro-microscopy (SEM, JSM-6300, JOEL), Thermo gravimetric analysis (TGA, TG/DTA 6200, SII Exstar6000, heating rate of $5 \mathrm{~K}$ per minute under $\mathrm{N}_{2}$ atmosphere) and X-ray diffraction (XRD, Rigaku Denki RINT 2000, X-ray $\lambda_{\mathrm{Cu} k \alpha}=0.154 \mathrm{~nm}$ ). In addition, $\mathrm{N}_{2}$ sorption isotherm at $77 \mathrm{~K}$ was used to calculate the specific surface area (SSA) using the Brunauer-Emmet-Teller (BET) equation (Yuasa Ionics Autosorb-6, samples were degassed at $353 \mathrm{~K}$ for 2 $\mathrm{h}$ prior to determination ).

\subsection{Data analysis}

\subsubsection{Adsorption kinetics}

To study the sorption kinetics, we used the pseudo-first-order and pseudo-second-order rate models [18]. 
The pseudo-first-order rate equation of Lagergren is as follows:

$$
\frac{d q_{t}}{d t}=K_{1}\left(q_{e}-q_{t}\right)
$$

Applying with the boundary conditions $\left(\mathrm{t}=0, q_{t}=0\right)$ and then integrating, we have:

$$
q_{t}=q_{e}\left(1-e^{-K_{2} t}\right)
$$

where $q_{e}, q_{t}$ respectively represent the adsorption capacities at the equilibrium and as each sampling time $\left(\mathrm{g} \mathrm{g}^{-1}\right) ; K_{1}$ is the rate constant of the pseudo-first-order adsorption $\left(\mathrm{min}^{-1}\right)$.

The pseudo-second-order rate equation is written as:

$$
\frac{d q_{t}}{d t}=K_{1}\left(q_{e}-q_{t}\right)^{2}
$$

By integration with the above-mentioned conditions, it is converted to:

$$
q_{t}=\frac{K_{2} q_{e}^{2} t}{1+K_{2} q_{e} t}
$$

where $q_{e}, q_{t}$ represent the adsorption capacity at equilibrium and at every interval $\left(\mathrm{mg} \mathrm{g}^{-1}\right)$, respectively; $K_{2}$ is the rate constant of adsorption for the pseudo-second-order model $\left(\mathrm{g} \mathrm{g}^{-1} \mathrm{~min}^{-1}\right)$; $K_{2} q_{e}^{2}$ is the initial adsorption rate $\left(\mathrm{mg} \mathrm{g}^{-1} \min ^{-1}\right)$.

The adsorption initial rates were respectively calculated as:

$$
\begin{aligned}
& h_{0,1}=K_{1} q_{e} \\
& h_{0,2}=K_{2} q_{e}^{2}
\end{aligned}
$$

where $h_{0,1}, h_{0,2}$ represent the initial rates calculated from pseudo first- and second-order rate models, $\left(\mathrm{mg} \min ^{-1} \mathrm{~g}^{-1}\right)$.

Web-Morris model was used to describe the pore diffusion $[19,20]$. It depends on the most solute uptake varying almost proportionally with the evolution of contact time, which is written as follows:

$$
q_{t}=K_{\mathrm{int}} t^{0.5}+C
$$

where $K_{\text {int }}$ is the pore diffusion rate constant $\left(\mathrm{mg} \mathrm{g}^{-1} \min ^{0.5}\right), C$ relates to the thickness of the boundary. 
Non-linear Langmuir (Eq. 9) and Freundlich (Eq. 10) isotherm equations were used as follows [12]:

$$
\begin{aligned}
& q_{e}=\frac{q_{m} K_{L} C_{e}}{1+K_{L} C_{e}} \\
& q_{e}=K_{F} C_{e}^{1 / n}
\end{aligned}
$$

where $q_{e}$ is the equilibrium adsorption capacity $\left(\mathrm{g} \mathrm{g}^{-1}\right) ; C_{e}$ is the equilibrium concentration $\left(\mathrm{g} \mathrm{L}^{-1}\right) ; q_{m}$ is the maximum adsorption capacity $\left(\mathrm{g} \mathrm{g}^{-1}\right) ; K_{m}$ is the Langmuir adsorptive constant related to the energy of adsorption $\left(\mathrm{L} \mathrm{g} \mathrm{g}^{-1}\right) ; K_{F}$ is the Freundlich adsorptive constant related to the adsorption energy $\left(\mathrm{L} \mathrm{g}^{-1}\right)$, and $1 / n$ is the dimensionless heterogeneity factor.

\section{Results and discussion}

3.1. GO-involving preparation and structural change of the hybrid absorbents

GO (Fig. 1a) was mass produced from expanded graphite via a modified Hummers method in our lab [17]. In the AFM image, we could clearly see the 2D GO sheets with the sizes of micrometer in length and nearly $1 \mathrm{~nm}$ in thickness vs. $0.35 \mathrm{~nm}$ of graphene owing to the implantation of plenty of oxygen-containing functionalities onto both sides of graphene (Fig. 1b). It suggested a completed exfoliation of graphite. The ionization of these functional groups had GO negatively charged ( $\zeta$-potential $\sim-54 \mathrm{mV}$ ) and highly colloidal-like stable in water (over 12 months).

XRD was used to verify the interaction between alginate and GO. The patterns of GO, sodium alginate and their hybrid film were shown in Fig. 1c. GO had a dominant (100) peak around 11.6 ${ }^{\circ}$, indicating the interlayer spacing around 7.6 A. Alginate had two typical peaks around 15 (110) and $22.5^{\circ}$ (002), respectively corresponding to the lateral packing among molecular chains and the layer spacing along the molecular chain direction [21]. No distinct difference occurred before and after the addition of GO except a small decrease of spacing from $6.01 \AA\left(15.9^{\circ}, \mathrm{SA}\right)$ to $5.74 \AA\left(15.3^{\circ}, \mathrm{SA}-\mathrm{GO}\right)$, which indicated an interaction of carboxyl and hydroxyl groups between alginate and GO [22]. And the characteristic peak of GO disappeared, further proved that GO was well distributed in alginate matrix. Therefore the hybrid solution was demonstrated highly homogenous.

It is noting that $\mathrm{CaCO}_{3}$ was used, yet requiring of being well dispersed in hybrid solution before reaction to $\mathrm{HCl}$. Thus they suffered a ball milling (size $>3 \mu \mathrm{m}$, almost $100 \%$, before; to less than $25 \%$, 


\section{ACCEPTED MANUSCRIPT}

after) and became more easily dispersible [23]. Sodium alginate is reportedly capable of mono-dispersing water-insoluble materials, i.e., MWCNTs [24]. To disperse $\mathrm{CaCO}_{3}$ remained unsatisfying even with a vigorous stirring, ultra-sonication and even alginate concentration increased up to $2.5 \mathrm{wt} \%$. GO was also ever used in this regard [25]. A stable GO/calcium carbonate binary suspension was satisfactorily firstly prepared and stably mixed with alginate. As a result, all hybrid beads were prepared within minutes at a scale of kilogram (Figs. 2A - D).

As measured, the wet beads had sizes in order: SA-GO-M $(5.40 \pm 0.55 \mathrm{~mm})>$ Pure SA-M $(4.78$ $\pm 0.41 \mathrm{~mm})$, SA-GO-N $(3.64 \pm 0.25 \mathrm{~mm})>$ Pure SA-N $(3.35 \pm 0.24 \mathrm{~mm})$. We could find these beads with GO had larger sizes. Besides, calcium beads (Pure SA-N and SA-GO-N) sunk in water at the bottom (Figs. 2A and C), while porous alginic beads (Pure SA-M and SA-GO-M) suspended (Figs. 2B and D), demonstrating their lower densities. Similarly of the dry weight, the freeze-dried beads (Fig. 2E) were lighter if in presence of GO. From the BET data, we had SSA in the order: SA-GO-M $\left(31.3 \mathrm{~m}^{2} \mathrm{~g}^{-1}\right)>$ Pure SA-M (11.4 $\left.\mathrm{m}^{2} \mathrm{~g}^{-1}\right)$, SA-GO-N $\left(22.9 \mathrm{~m}^{2} \mathrm{~g}^{-1}\right)>$ Pure SA-N $\left(0.4 \mathrm{~m}^{2} \mathrm{~g}^{-1}\right)$. Incorporating GO demonstrated to increase the SSA by around 1.8 fold (alginic beads) or 56.2 fold (calcium beads). Moreover, it clearly indicated the calcium beads" "cell wall" got drastically decreased of their thickness from up to $20 \mu \mathrm{m}$ (Figs.2F and G). And these beads turned out to be more porous when GO involved. It was quite similar for those alginic beads (Figs. $2 \mathrm{H}$ and I), but the accumulation of gaseous $\mathrm{CO}_{2}$ resulted in more macroporous as compared for GO-encapsulating beads. We stress here that due to preparation itself, alginic beads were of channel structures with their ends open to outside, different from that of calcium beads which had much isolated pore system. Owing to this property, it allowed fast ion diffusion and thus favorable for adsorptions.

FTIR spectroscopy was used to confirm the gelation (Fig. 3a). As compared, the inclusion of GO broadened the peaks at around $3398 \mathrm{~cm}^{-1}$, indicating the interaction of GO and alginate [26]. These peaks at $1415 \mathrm{~cm}^{-1}$ and $1595 \mathrm{~cm}^{-1}$ were assignable to the symmetric and asymmetric stretching vibrations of carboxylate in those metal alginate, respectively; by contrast, a peak shifted to $1728 \mathrm{~cm}^{-1}$ represented the typical vibration of carbonyl stretching for acidized alginate [27]. Historically mild acidifications was used to release calcium ions from various calcium complexes (calcium citrate, calcium carbonate, etc.) to crosslink alginate, e.g., glacial acetic acid [28]. We expected that concentrated $\mathrm{HCl}$ instead would help 
fast release $\mathrm{CO}_{2}$ to pore promotion and $\mathrm{Ca}^{2+}$ to simultaneously cross-link alginate. However due to the extreme concentration of $\mathrm{H}^{+}$and the $\mathrm{pH}$ far below the pKa of alginate (around 4.2) [29], alginic acid was consequently obtained (Pure Sa-M, SA-GO-M). Interestingly, though the strength was not high enough as calcium alginate, their adsorption capabilities got improved, the same as the reported [30].

To clarify the thermal tolerance, the temperature-mass relation was studied by means of TGA (Fig. 3b). All adsorbents were quite stable even at the temperature over $373.15 \mathrm{~K}$. The temperature-responsive mass evolution was two-stage process: the adsorbed/ hydrated water went lost at temperatures, up to 474 $\mathrm{K}$ for calcium beads, and $431 \mathrm{~K}$ for alginic beads; and then the rupture of chains, fragments and monolayers of alginate and decomposition of GO [12, 31]. Taking calcium beads as an example, the increased porosity by GO got more water possibly immobilized via hydrogen bonding, etc. Thus it implied that the hybrid adsorbent had more active sites. On the other hand, since GO riches in surface-decorating oxygen functional groups, and is intrinsically thermally instable, more weight loss would suffer as shown. The marked intragroup discrimination on their respective residuals could be understandable from the aspect of their compositions. Annealing under $\mathrm{N}_{2}$ at less than $873 \mathrm{~K}$ carbonized calcium beads (release composited water and carbon oxide, etc.) and produced calcium carbonate, while the former was the main process for alginic beads. In addition, the intergroup residual difference was closely related to their structures. A great residual decrease by $\sim 22 \%$ was preferentially attributable to the remarkable increase of surface area (Pure SA-N $\sim 52.2 \%$, while SA-GO-N $\sim 30.6 \%$ ), while no obvious difference was observed for alginic beads (Pure SA-N 20.4\%, and SA-GO-N 17.7\%).

\subsection{Influence of $G O$ from kinetic studies}

To ascertain the suitability as absorbents, the time-versus-residual data was recorded under identical conditions (Fig. 4a-1 and a-2). We found all adsorptions reached the equilibrium at a time less than $3 \mathrm{~h}$, except for the Pure SA-N. And the color of all beads turned dark red from transparent. This indicated a strong interaction between oppositely charged alginate-based beads and dye molecules [6]. Consistent to the structure-related speculations (TGA and SEM), GO indicated helpfulness to the equilibrium time consumption, the adsorptive kinetics and the removal efficiencies, especially for calcium beads. More specifically, the average adsorptive rates were in the order: SA-GO-N $\left(0.19 \mathrm{mg} \mathrm{g}^{-1} \mathrm{~min}^{-1}\right)>$ Pure SA-N $\left(0.07 \mathrm{mg} \mathrm{g}^{-1} \mathrm{~min}^{-1}\right)$; SA-GO-M $\left(0.21 \mathrm{mg} \mathrm{g}^{-1} \mathrm{~min}^{-1}\right)>$ Pure SA-M $\left(0.20 \mathrm{mg} \mathrm{g}^{-1} \mathrm{~min}^{-1}\right)$; while the same 
$(93.6 \%)>$ Pure SA-M (92.4\%). As compared, the insignificant increase of efficiency for alginic absorbents showed that the preparation protocol, other than GO, played a dominant role on performance since it brought absorbents with an open structure. We found that GO as a "porogen" would influence to a larger extent when entrapped inside a matrix with a closed structure disadvantageous for ion diffusion [6].

Non-linear pseudo first-order (Eq. 3), non-linear pseudo-second order rate (Eq. 5), and Web-Morris pore diffusion (Eq. 8) models were used to fit the adsorption data (Figs. 4b-c). The suitability was determined by the correlation coefficient value $\left(\mathrm{R}^{2}\right)$. Of note, non-linearized forms of the model equations doesn't suit to describe the adsorption kinetics [32]. The estimated parameters were listed in Tab. 1. As shown, pseudo first- and second-order rate models both had nice fittings $\left(\mathrm{R}^{2}>0.98\right)$; but the former was even better due to the higher coefficients. And also the calculated $q_{e, c a l}$ values agreed well to the experimental ones. Higher $K_{1}$ and $K_{2}$ values indicated less time to the equilibrium [19]. The initial adsorption rates had the order: SA-GO-M (4.382 $\left.\mathrm{mg} \mathrm{min}^{-1} \mathrm{~g}^{-1}\right)>$ Pure SA-M (3.131 $\left.\mathrm{mg} \mathrm{min}^{-1} \mathrm{~g}^{-1}\right)$; SA-GO-N (1.277 mg $\left.\min ^{-1} \mathrm{~g}^{-1}\right)>$ Purer SA-N $\left(0.257 \mathrm{mg} \mathrm{min}^{-1} \mathrm{~g}^{-1}\right)$. They verified that GO involved adsorptions were superior, and this advantages became clearer on calcium beads over alginic ones, as the equilibrium time differences shown (Figs. 4a-1 and a-2).

Fig. $4 \mathrm{c}$ presents the pore diffusion plot of $\mathrm{AO}$ adsorption. In principle if the pore diffusion plays as a rate-limiting step, the plot would give a straight line through the origin with an intercept that equals to zero. It is clear that the plots were multi-linear, having at least two linear segments. Combining with the regression results in Tab. 1, they had the intercepts impossibly being zero even for the first segments in the case of Pure SA-M and SA-GO-M $\left(\mathrm{R}^{2}<0.9\right)$, which meant the external film diffusion undertook the rate-limiting factor at the initial stage $[19,20]$; while the fittings had higher co-efficiencies $\left(\mathrm{R}^{2}>0.9\right)$ in the case of calcium beads, indicative of the pore diffusion as a rate-limiting step to the overall rate. And the following segment was assigned to the equilibrium stage. Moreover on the first segments, the results were also understandable by considering the structural differences that SEM images exhibited, where calcium beads had a relatively closed structure restricting adsorbates of fast entering as compared to that 
of alginic beads. In both cases, we found that faster pore diffusion occurred when the adsorptions related to GO from their higher $K_{\text {int }}$ values.

\subsection{Isotherm studies}

Fig. 5 shows the equilibrium concentration-versus-capacity plot with the purpose to investigate the isothermal characteristics. A common tendency was deduced that the adsorptive capacity increased with AO equilibrium concentrations, and afterwards gradually reached the plateau maximum. Their experimental capacities were: SA-GO-M $\left(1.351 \mathrm{~g} \mathrm{~g}^{-1}\right)>$ Pure SA-M $\left(1.176 \mathrm{~g} \mathrm{~g}^{-1}\right)$, SA-GO-N $\left(0.797 \mathrm{~g} \mathrm{~g}^{-1}\right)$ $>$ Pure SA-N (0.378 $\left.\mathrm{g} \mathrm{g}^{-1}\right)$ (Tab. 2). The incorporation of GO almost doubled the capacity of calcium beads and increased by nearly $15 \%$ for alginic beads.

Non-linear Langmuir (Eq. 9) and Freundlich (Eq. 10) models were used to identify their adsorption behaviors (Fig.5 and Tab.2). The former is established with assuming the monolayer coverage of solute over specific homogeneous sites within the sorbent $[12,13,19,20]$; for the latter, it describes that the sorption energy exponentially decreases on the complexation of the sorptional centers of an sorbent and an indicated heterogeneous system [31]. From the results, we can understand that the Langmuir model better evaluated over Freundlich because of the higher coefficients $\left(\mathrm{R}^{2}>0.9\right)$. It was then believed the adsorption of AO followed a site-to-site behavior. And consequently the theoretical maximum capacities were calculated and found quite agreeable to the experimental values. Moreover in comparison with the already-reported adsorption systems in Tab. 3, our absorbents, especially those with GO demonstrated relatively competitive capacities, for example, the SA-GO-M $\left(4.5 \mathrm{mmol} \mathrm{g}^{-1}\right)$ vs. GO $\left(4.7 \mathrm{mmol} \mathrm{g}^{-1}\right)$; GO and GO-derived adsorbents were already demonstrated having excellent kinetics properties over various contaminants, which was also verified in our cases. Introducing GO as one component have had considerably improved our decontamination by further decreasing of equilibrium time, for example.

\subsection{Mechanism and $\mathrm{pH}$ responsive performances}

Carboxyl group makes alginate itself intrinsically capable of ion-exchange with positively charged inorganic/organic substances, such as $\mathrm{H}^{+}, \mathrm{Ca}^{2+}, \mathrm{Fe}^{3+}[6]$, and methylene blue [5]. This mechanism has addressed a majority of conventional adsorptive applications by taking alginate as adsorbents. To justify this proposal, solution $\mathrm{pH}$ changes were tracked before and after adsorption. The bulk AO solution was acidic, at $\mathrm{pH} \sim 5.1$. After adsorption the value became lower in the case of alginic bead, but higher for 
calcium beads (Fig. 6a). Together with the mentioned site-to-site adsorptive behavior, we well understood the ion-exchange mechanism mainly took place. That is the $\mathrm{pH}$ closely related to the release of $\mathrm{H}^{+}$(Eq. 11) and $\mathrm{Ca}^{2+}$ (Eq. 12). Impressively, the varying degree of $\mathrm{pH}$ seriously depended on whether GO was used (SA-GO-M $\sim 3.96<$ Pure SA-M $\sim 4.26$; Pure SA-N $\sim 5.85<$ SA-GO-N 5.99), highly identical to the results of $\mathrm{AO}$ adsorption. It was thus probable that the encapsulation of GO provided more active sites for ion exchanging.

$$
\begin{aligned}
& \text { Bead }-\mathrm{AO}+\mathrm{H}^{+} \leftrightarrow \text { Bead }-\mathrm{H}^{+}+\mathrm{AO} \\
& \text { Bead }-\mathrm{AO}+\mathrm{Ca}^{2+} \leftrightarrow \text { Bead }-\mathrm{Ca}^{2+}+\mathrm{AO}
\end{aligned}
$$

We further simply immersed the dyed beads back into a freshly-prepared $\mathrm{CaCl}_{2}$ solution (Fig. $6 \mathrm{~b}$ ). The colorless solution instantly changed to yellow (the color of AO), proving the replacement/desorption of $\mathrm{AO}$ with $\mathrm{Ca}^{2+}$ and very fast once they contacted. By contrast, the control group (in deionized water only) had no change even under a long-term shaking (200 rpm, $72 \mathrm{~h})$.

To investigate the effect of $\mathrm{pH}$ on encapsulated $\mathrm{GO}$, dye adsorptions were executed in solutions at a certain range of $\mathrm{pH}$ less than 10 (Fig. 6c), where AO was still kept protonated (the pKa of AO 10.4) [33]. As it showed, the overall capacity increased with $\mathrm{pH}$. Under acidic condition carboxylate groups of alginate and GO became progressively protonated, then the content of $\mathrm{Ca}^{2+}$ in the beads decreased [34]; in the meantime, a concentration-dependent competitive adsorption existed between $\mathrm{H}^{+}$and cationic dye. In the case of higher $\mathrm{pH}$, more oxygen-containing functional groups became dissociated, favorable for ion-exchanging; and as $\mathrm{pH}$ further increased, these absorbents turned more negatively charged. The electrostatic attraction then worked and took secondarily important role, yet leading adsorption systems to less ability, as concluded from somewhat decreased capacities under $\mathrm{pH} 6$ to $8[19,34]$.

GO had as mentioned well improved the adsorptive performance. We were aware that at $\mathrm{pH} \sim 2, \mathrm{GO}$ remained highly contributed while alginate was much inhibited. This was attributed to GO's multiple interactions with AO. The adsorption by GO relied on not only its $\mathrm{pH}$-dependent dissociable oxygen functional groups [35], but also other effects, like $\pi-\pi$ stacking, etc.. To our knowledge, GO-relative adsorptions obeyed the Langmuir behavior in the vast majority of cases, wherever it suffered reduction or not [12], like adsorbing $\mathrm{Cu}^{2+}[36], \mathrm{Pb}^{2+}, 1$-naphthol and 1-naphthylamine [37], etc. Therefore we believed that the incorporation of GO would favor extending the utilizable area for alginate-based absorbents. 


\section{Conclusions}

GO was encapsulated inside the alginate and porous alginic beads. The good incorporation of GO showed to promote the hybrid absorbents more porous. Thus it was found to have improved adsorptive kinetics as well. Isotherm studies indicated all adsorptions well fitted to the description by Langmuir isotherm model. And our adsorbents had comparably high adsorptive capacities as compared to those reported. Besides, the applicable $\mathrm{pH}$ range of decontamination was extended to some extent. From these aspects, GO/alginate-based adsorbent systems would provide one promising alternative in water cleanup arena.

\section{Acknowledgments}

The author (Ling Sun) would like to acknowledge the China Scholarship Council (CSC) scholarship for the living support in Japan (File No. 2008643024), and also Hokkaido University for the tuition-free scholarship.

\section{References}

[1] H.G. Park, M.Y. Chae, Novel type of alginate gel-based adsorbents for heavy metal removal, J. Chem. Technol. Biotechnol., 79 (2004) 1080-1083.

[2] N.F.Y. Tam, Y.S. Wong, C.G. Simpson, Repeated removal of copper by alginate beads and the enhancement by microalgae, Biotechnol. Tech., 12 (1998) 187-190.

[3] S.P. Kuhn, R.M. Pfister, Adsorption of mixed metals and cadmium by calcium-alginate immobilized Zoogloea ramigera, Appl. Microbiol. Biotechnol., 31 (1989) 613-618.

[4] L. Ai, C. Zhang, Z. Chen, Removal of methylene blue from aqueous solution by a solvothermal-synthesized graphene/magnetite composite, J. Hazard. Mater., 192 (2011) 1515-1524.

[5] V. Rocher, J.M. Siaugue, V. Cabuil, A. Bee, Removal of organic dyes by magnetic alginate beads, Water Res., 42 (2008) 1290-1298.

[6] Y.B. Lin, B. Fugetsu, N. Terui, S. Tanaka, Removal of organic compounds by alginate gel beads with entrapped activated carbon, J. Hazard. Mater., 120 (2005) 237-241. 


\section{ACCEPTED MANUSCRIPT}

[7] B. Fugetsu, S. Satoh, T. Shiba, T. Mizutani, Y.B. Lin, N. Terui, Y. Nodasaka, K. Sasa, K. Shimizu, R. Akasaka, M. Shindoh, K.I. Shibata, A. Yokoyama, M. Mori, K. Tanaka, Y. Sato, K. Tohji, S. Tanaka, N. Nishi, F. Watari, Caged multiwalled carbon nanotubes as the adsorbents for affinity-based elimination of ionic dyes, Environ. Sci. Technol., 38 (2004) 6890-6896.

[8] E.G. Deze, S.K. Papageorgiou, E.P. Favvas, F.K. Katsaros, Porous alginate aerogel beads for effective and rapid heavy metal sorption from aqueous solutions: Effect of porosity in $\mathrm{Cu}^{2+}$ and $\mathrm{Cd}^{2+}$ ion sorption, Chem. Eng. J., 209 (2012) 537-546.

[9] G. Zhao, J. Li, X. Ren, C. Chen, X. Wang, Few-layered graphene oxide nanosheets as superior sorbents for heavy metal ion pollution management, Environ. Sci. Technol., 45 (2011) 10454-10462.

[10] G.X. Zhao, X.M. Ren, X. Gao, X.L. Tan, J.X. Li, C.L. Chen, Y.Y. Huang, X.K. Wang, Removal of $\mathrm{Pb}$ (II) ions from aqueous solutions on few-layered graphene oxide nanosheets, Dalton Trans., 40 (2011) 10945-10952.

[11] Y. Gao, Y. Li, L. Zhang, H. Huang, J. Hu, S.M. Shah, X. Su, Adsorption and removal of tetracycline antibiotics from aqueous solution by graphene oxide, J. Colloid Interface Sci., 368 (2012) 540-546.

[12] L. Sun, H. Yu, B. Fugetsu, Graphene oxide adsorption enhanced by in situ reduction with sodium hydrosulfite to remove acridine orange from aqueous solution, J. Hazard. Mater., 203-204 (2012) $101-110$

[13] L. Fan, C. Luo, M. Sun, X. Li, F. Lu, H. Qiu, Preparation of novel magnetic chitosan/graphene oxide composite as effective adsorbents toward methylene blue, Bioresour. Technol., 114 (2012) 703-706.

[14] W.M. Algothmi, N.M. Bandaru, Y. Yu, J.G. Shapter, A.V. Ellis, Alginate-graphene oxide hybrid gel beads: an efficient copper adsorbent material, J. Colloid Interface Sci., 397 (2013) 32-38.

[15] K. Wang, J. Ruan, H. Song, J.L. Zhang, Y. Wo, S.W. Guo, D.X. Cui, Biocompatibility of graphene Oxide, Nanoscale Res. Lett., 6 (2011) 8. 


\section{ACCEPTED MANUSCRIPT}

[16] A. Schinwald, F.A. Murphy, A. Jones, W. MacNee, K. Donaldson, Graphene-based nanoplatelets: a new risk to the respiratory system as a consequence of their unusual aerodynamic properties, ACS Nano, $6(2011) 736-746$.

[17] L. Sun, B. Fugetsu, Mass production of graphene oxide from expanded graphite, Mater Lett, 109 (2013) 207-210.

[18] Y.S. Ho, G. McKay, Pseudo-second order model for sorption processes, Process Biochem., 34 (1999) 451-465.

[19] B.H. Hameed, M.I. El-Khaiary, Malachite green adsorption by rattan sawdust: isotherm, kinetic and mechanism modeling, J. Hazard. Mater., 159 (2008) 574-579.

[20] H. Zheng, D.H. Liu, Y. Zheng, S.P. Liang, Z. Liu, Sorption isotherm and kinetic modeling of aniline on Cr-bentonite, J. Hazard. Mater., 167 (2009) 141-147.

[21] L.B. Li, Y.P. Fang, R. Vreeker, I. Appelqvist, Reexamining the egg-box model in calcium-alginate gels with X-ray diffraction, Biomacromolecules, 8 (2007) 464-468.

[22] G. Yang, L. Zhang, T. Peng, W. Zhong, Effects of $\mathrm{Ca}^{2+}$ bridge cross-linking on structure and pervaporation of cellulose/alginate blend membranes, J Membrane Sci, 175 (2000) 53-60.

[23] B. Hu, B. Fugetsu, H. Yu, Y. Abe, Prussian blue caged in spongiform adsorbents using diatomite and carbon nanotubes for elimination of cesium, J. Hazard. Mater., 217-218 (2012) 85-91.

[24] B. Fugetsu, E. Sano, M. Sunada, Y. Sambongi, T. Shibuya, X.S. Wang, T. Hiraki, Electrical conductivity and electromagnetic interference shielding efficiency of carbon nanotube/cellulose composite paper, Carbon, 46 (2008) 1256-1258.

[25] J. Kim, L.J. Cote, F. Kim, W. Yuan, K.R. Shull, J.X. Huang, Graphene oxide sheets at interfaces, J. Am. Chem. Soc., 132 (2010) 8180-8186.

[26] Y. He, N. Zhang, Q. Gong, H. Qiu, W. Wang, Y. Liu, J. Gao, Alginate/graphene oxide fibers with enhanced mechanical strength prepared by wet spinning, Carbohydr. Polym., 88 (2012) 1100-1108. 


\section{ACCEPTED MANUSCRIPT}

[27] S.K. Papageorgiou, E.P. Kouvelos, E.P. Favvas, A.A. Sapalidis, G.E. Romanos, F.K. Katsaros, Metal-carboxylate interactions in metal-alginate complexes studied with FTIR spectroscopy, Carbohydr. Res., 345 (2010) 469-473.

[28] D. Poncelet, B. Poncelet De Smet, C. Beaulieu, M.L. Huguet, A. Fournier, R.J. Neufeld, Production of alginate beads by emulsification/internal gelation. II. Physicochemistry, Appl. Microbiol. Biotechnol., 43 (1995) 644-650.

[29] R. Valentin, R. Horga, B. Bonelli, E. Garrone, F. Di Renzo, F. Quignard, Acidity of alginate aerogels studied by FTIR spectroscopy of probe molecules, Macromol. Symp., 230 (2005) 71-77.

[30] Y.M. Qin, H.Q. Hu, A.X. Luo, The conversion of calcium alginate fibers into alginic acid fibers and sodium alginate fibers, J. Appl. Polym. Sci., 101 (2006) 4216-4221.

[31] H. Dogan, Preparation and characterization of calcium alginate-based composite adsorbents for the removal of $\mathrm{Cd}, \mathrm{Hg}$, and $\mathrm{Pb}$ ions from aqueous solution, Toxicol. Environ. Chem., 94 (2012) 482-499.

[32] K.V. Kumar, S. Sivanesan, Selection of optimum sorption kinetics: comparison of linear and non-linear method, J. Hazard. Mater., 134 (2006) 277-279.

[33] G. Lv, Z. Li, W.-T. Jiang, P.-H. Chang, J.-S. Jean, K.-H. Lin, Mechanism of acridine orange removal from water by low-charge swelling clays, Chem. Eng. J., 174 (2011) 603-611.

[34] V. Rocher, A. Bee, J.M. Siaugue, V. Cabuil, Dye removal from aqueous solution by magnetic alginate beads crosslinked with epichlorohydrin, J. Hazard. Mater., 178 (2010) 434-439.

[35] C.J. Zhou, W.J. Zhang, W.C. Zhou, A.H. Lei, Q.L. Zhang, Q. Wan, B.S. Zou, Fast and considerable adsorption of methylene blue dye onto graphene oxide, Bull. Environ. Contam. Toxicol., 87 (2011) 86-90.

[36] X. Mi, G. Huang, W. Xie, W. Wang, Y. Liu, J. Gao, Preparation of graphene oxide aerogel and its adsorption for $\mathrm{Cu}^{2+}$ ions, Carbon, 50 (2012) 4856-4864. 
[37] X. Yang, C. Chen, J. Li, G. Zhao, X. Ren, X. Wang, Graphene oxide-iron oxide and reduced graphene oxide-iron oxide hybrid materials for the removal of organic and inorganic pollutants, RSC Adv., 2 (2012) 8821. 


\section{Figure captions}

Fig. 1. GO solution (a), a typical AFM image of GO on freshly exfoliated mica with an inset profiles indicating the thickness of GO sheets $\sim 1 \mathrm{~nm}(\mathrm{~b})$ and the XRD patterns (c) of GO, alginate (SA), and alginate-GO film (SA-GO).

Fig. 2. Photographic and SEM images of Pure SA-N (A, F), SA-GO-N (C, G), Pure SA-M (B, H), and SA-GO-M (D, I) with the weight histogram (E).

Fig. 3. FTIR spectra of Pure SA-N, Pure SA-M, SA-GO-M and SA-GO-N and sodium alginate (a), and their thermogravimetric curves $\left(\mathrm{N}_{2}\right.$ atmosphere, heating rate of $5 \mathrm{~K} \mathrm{~min}^{-1}$, flow rate of $\left.90 \mathrm{~mL} \mathrm{~min}^{-1}\right)$ (b).

Fig. 4. Time-dependent adsorptions (a-1, a-2) of beads (AO: $\left.20 \mathrm{mg} \mathrm{L}^{-1}, \mathrm{pH} \sim 5\right)$ and data fitted by the pseudo-first-order rate and pseudo-second-order rate models (b), and Webber's diffusion model (c).

Fig. 5. Adsorption isotherms and their fittings by Langmuir and Freundlich models.

Fig. 6. Histogram of solution pH before and after adsorptions (AO: $20 \mathrm{mg} \mathrm{L}^{-1}$; beads amount: $6 \mathrm{mg}$ ) (a); and a photo indicative of solution color change once the dyed beads (SA-GO-M and SA-GO-N) were immersed in $\mathrm{CaCl}_{2}\left(0.5 \mathrm{~mol} \mathrm{~L}^{-1}\right)$ and deionized water (b); the dye adsorption of beads under an indicated $\mathrm{pH}$ range (AO: $\left.20 \mathrm{mg} \mathrm{L}^{-1}\right)(\mathrm{c})$. 


\section{Tables}

Tab. 1. Parameters for the pseudo-first-order rate model, the pseudo-second-order rate model and the Weber's pore-diffusion model.

\begin{tabular}{llllll}
\hline & Parameters & Pure SA-N & SA-GO-N & Pure-SA-M & SA-GO-M \\
Experimental & $q_{e}\left(\mathrm{mg} \mathrm{g}^{-1}\right)$ & 41.8 & 59.0 & 61.3 & 63.3 \\
Pseudo 1-order & $\mathrm{R}^{2}$ & 0.9927 & 0.9875 & 0.9976 & 0.9981 \\
& $K_{1}\left(\mathrm{~min}^{-1}\right)$ & 0.0060 & 0.0216 & 0.0517 & 0.0704 \\
& $q_{e, \text { cal }}\left(\mathrm{mg} \mathrm{g}^{-1}\right)$ & 42.86 & 59.10 & 60.57 & 62.25 \\
& $h_{0,1}\left(\mathrm{mg} \mathrm{min}^{-1} \mathrm{~g}^{-1}\right)$ & 0.257 & 1.277 & 3.131 & 4.382 \\
Pseudo 2-order & $\mathrm{R}^{2}$ & 0.9814 & 0.9857 & 0.9910 & 0.9957 \\
& $K_{2}$ & 0.1074 & 0.3071 & 1.0876 & 1.7851 \\
& $q_{e, \text { cal }}\left(\mathrm{mg} \mathrm{g}^{-1}\right)$ & 53.84 & 72.78 & 66.78 & 66.53 \\
& $h_{0,2}\left(\mathrm{mg} \mathrm{min}^{-1} \mathrm{~g}^{-1}\right)$ & 0.311 & 1.627 & 4.850 & 7.901 \\
Webber's & $\mathrm{R}^{2}$ & 0.900 & 0.930 & 0.871 & 0.249 \\
(First segment) & $K_{\text {inf }}\left(\mathrm{mg} \mathrm{g}^{-1} \mathrm{~min}^{0.5}\right)$ & 0.002 & 0.005 & 0.008 & 0.009 \\
\hline
\end{tabular}


Tab. 2 Fitting parameters for Langmuir and Freundlich isotherms.

\begin{tabular}{llllll}
\hline & Parameters & Pure SA-N & SA-GO-N & Pure SA-M & SA-GO-M \\
Experimental & $q_{m}\left(\mathrm{~g} \mathrm{~g}^{-1}\right)$ & 0.378 & 0.797 & 1.176 & 1.351 \\
Langmuir & $q_{m, c a l}\left(\mathrm{~g} \mathrm{~g}^{-1}\right)$ & 0.416 & 0.836 & 1.234 & 1.420 \\
& $\mathrm{R}^{2}$ & 0.917 & 0.988 & 0.989 & 0.992 \\
\multirow{2}{*}{ Freundlich } & $K_{L}\left(\mathrm{~L} \mathrm{~g}^{-1}\right)$ & 12.6 & 19.7 & 23.7 & 23.9 \\
& $\mathrm{R}^{2}$ & 0.820 & 0.924 & 0.895 & 0.890 \\
& $1 / n$ & 0.327 & 0.282 & 0.276 & 0.285 \\
& $K_{F}\left(\mathrm{~L} \mathrm{~g} \mathrm{~g}^{-1}\right)$ & 0.394 & 0.830 & 1.236 & 1.425 \\
\hline
\end{tabular}


Tab. 3. Adsorptions in literatures regarding alginate and/or cationic dyes.

\begin{tabular}{lllll}
\hline $\begin{array}{l}\text { Targeted } \\
\text { contaminants }\end{array}$ & $\begin{array}{l}\text { Capacity } \\
\left(\mathbf{m m o l ~} \mathbf{~}^{\mathbf{- 1}}\right)\end{array}$ & $\begin{array}{l}\text { Equilibrium time } \\
\mathbf{( m i n )}\end{array}$ & Sorbents & Literatures \\
\hline Methylene blue & 0.052 & $>392$ & Wet CaMB & (Rocher et al., 2010) \\
Methylene blue & 0.055 & $>105$ & Dry EpiMB-1 & (Rocher et al., 2010) \\
Methylene blue & 0.14 & $<5$ & GNS/Fe $\mathrm{O}_{4}$ & (Ai et al., 2011) \\
Methylene blue & 6.062 & $<5$ & GO & (Zhou et al., 2011) \\
p- Chlorophenol & 1.5 & $>100$ & AG-AC & (Lin et al., 2005) \\
AO & 1.2 & - & Swelling clays & (Lv et al., 2011) \\
AO & 4.7 & $<5$ & GO & (Sun et al., 2012) \\
AO & 1.2 & $>660$ & Pure SA-N & This work \\
AO & 2.6 & $<330$ & SA-GO-N & This work \\
AO & 3.7 & $<150$ & Pure SA-M & This work \\
AO & 4.5 & $<125$ & SA-GO-M & This work \\
\hline
\end{tabular}

- No mention. 
Figures and tables

Fig.1.
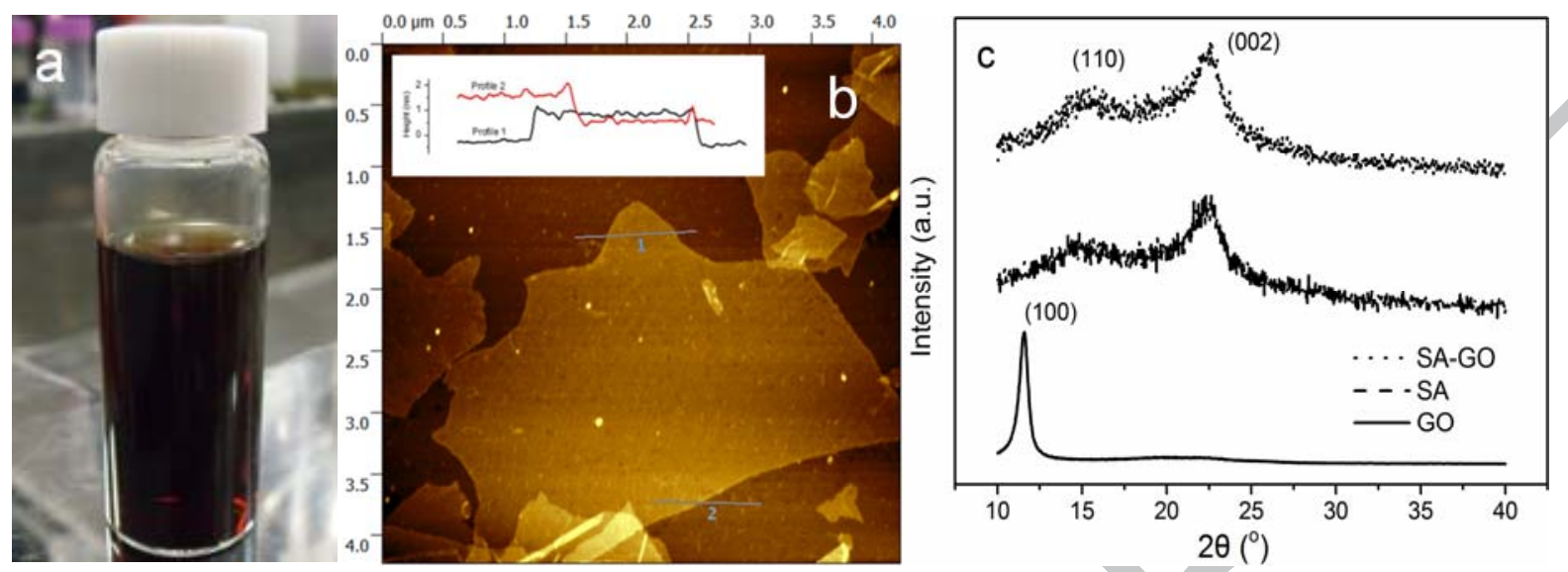


\section{ACCEPTED MANUSCRIPT}

Fig. 2.
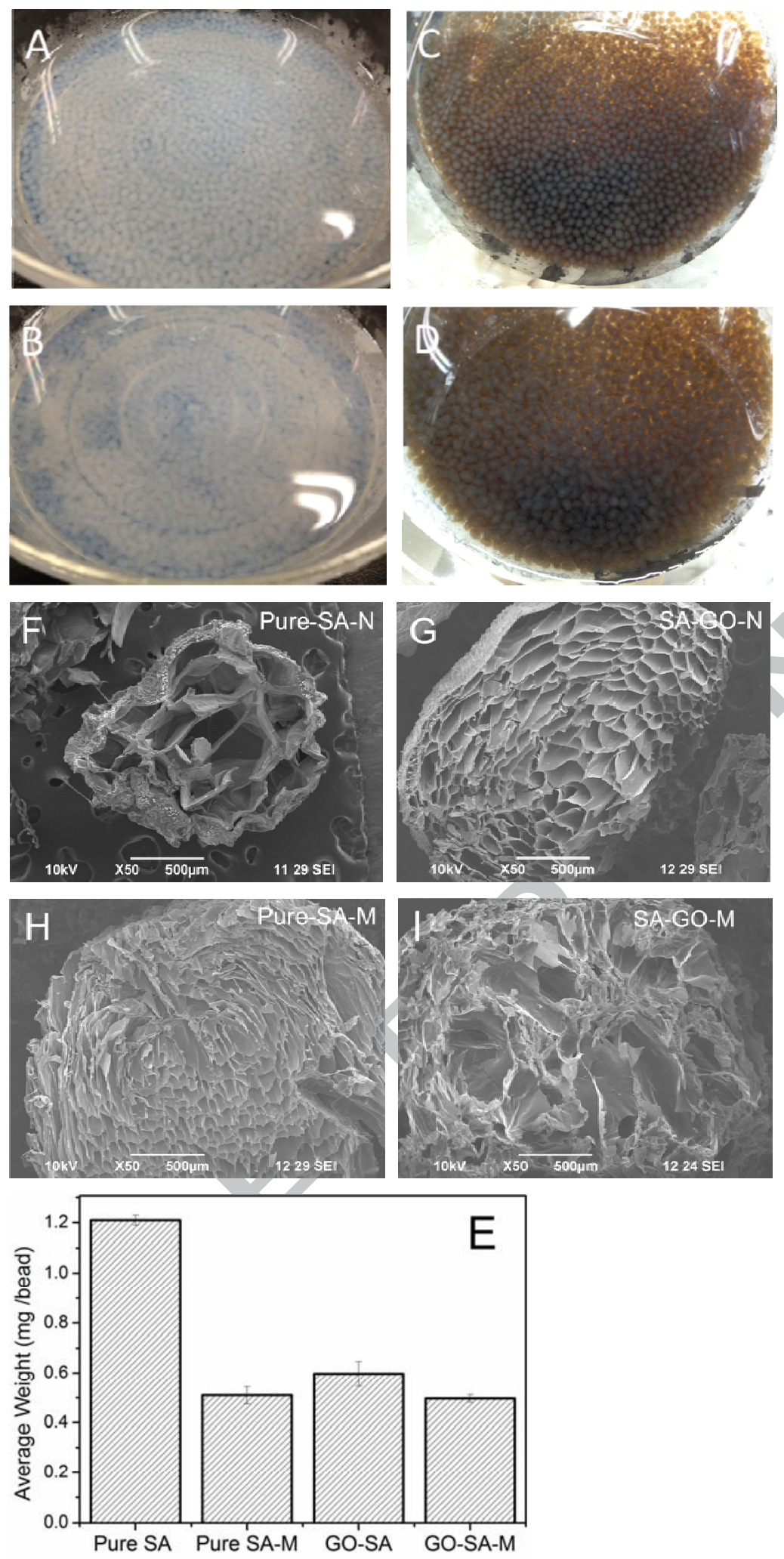


\section{ACCEPTED MANUSCRIPT}

Fig. 3.
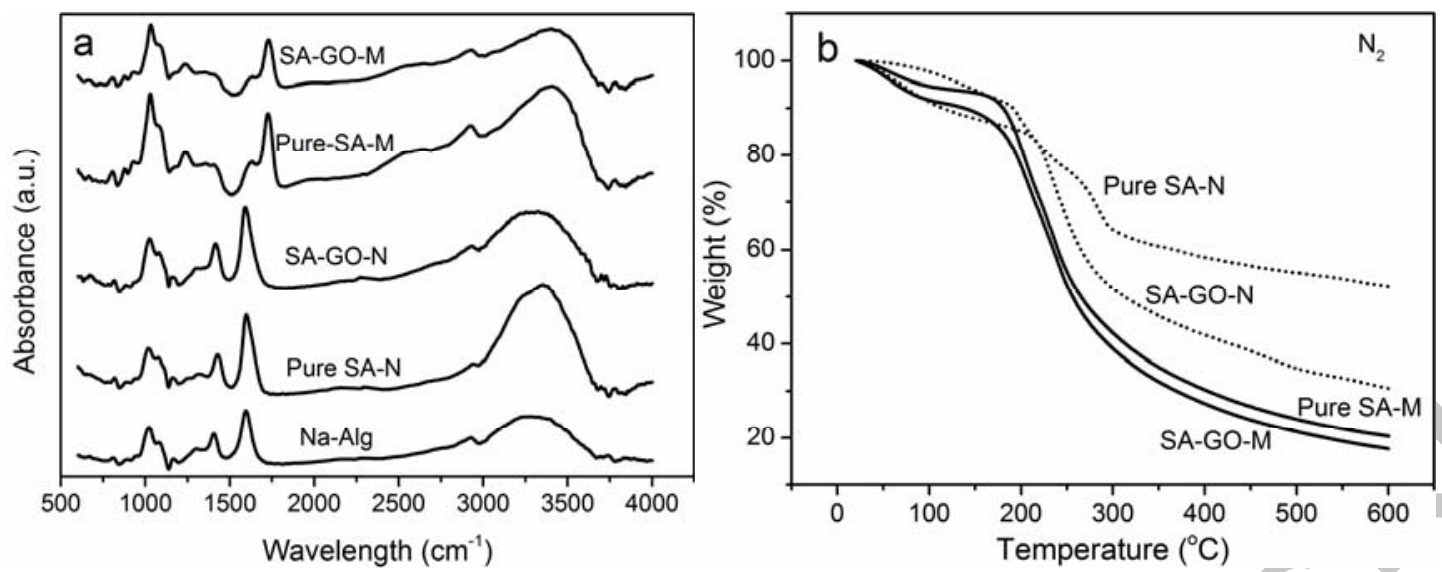
Fig. 4.
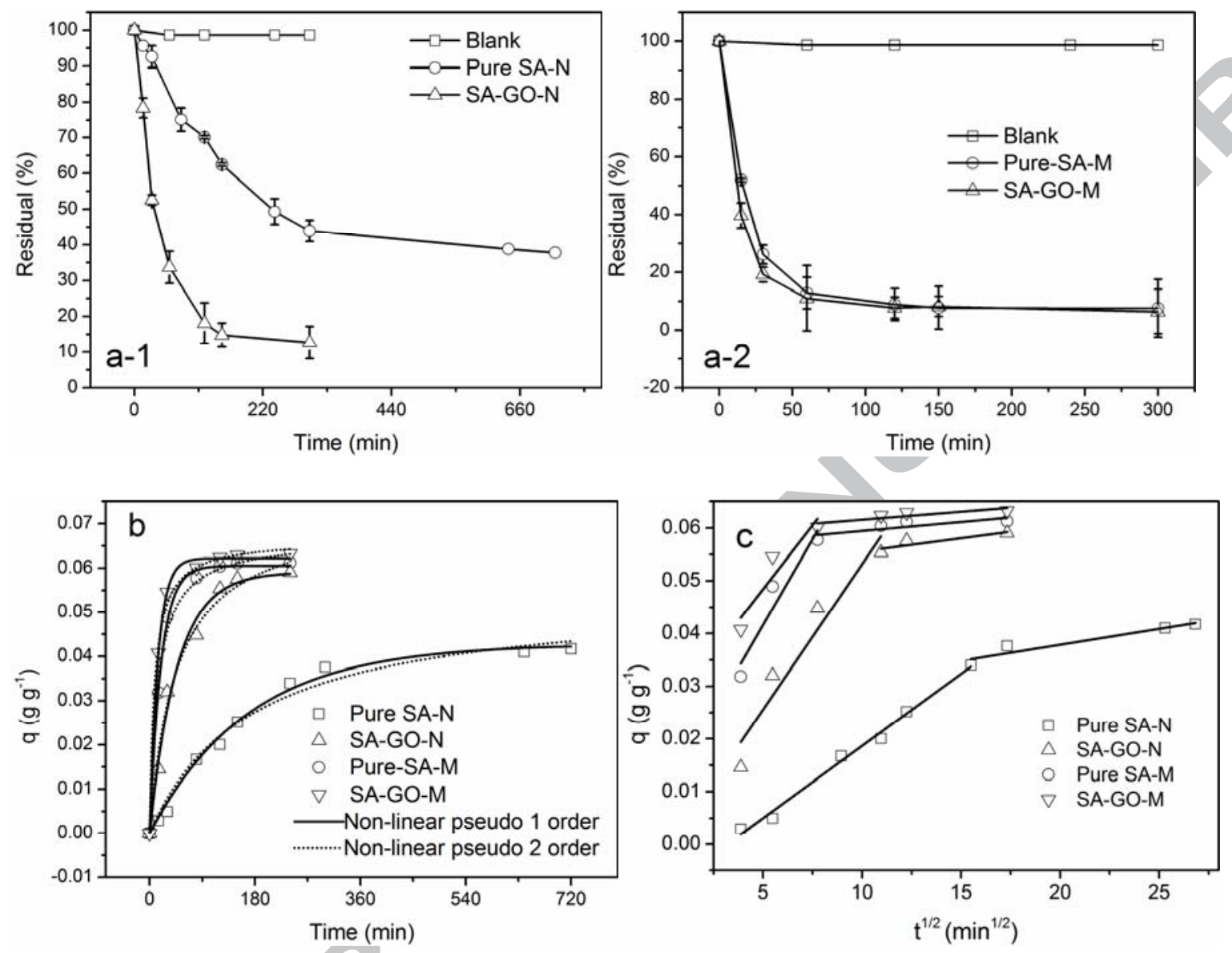
Fig. 5.

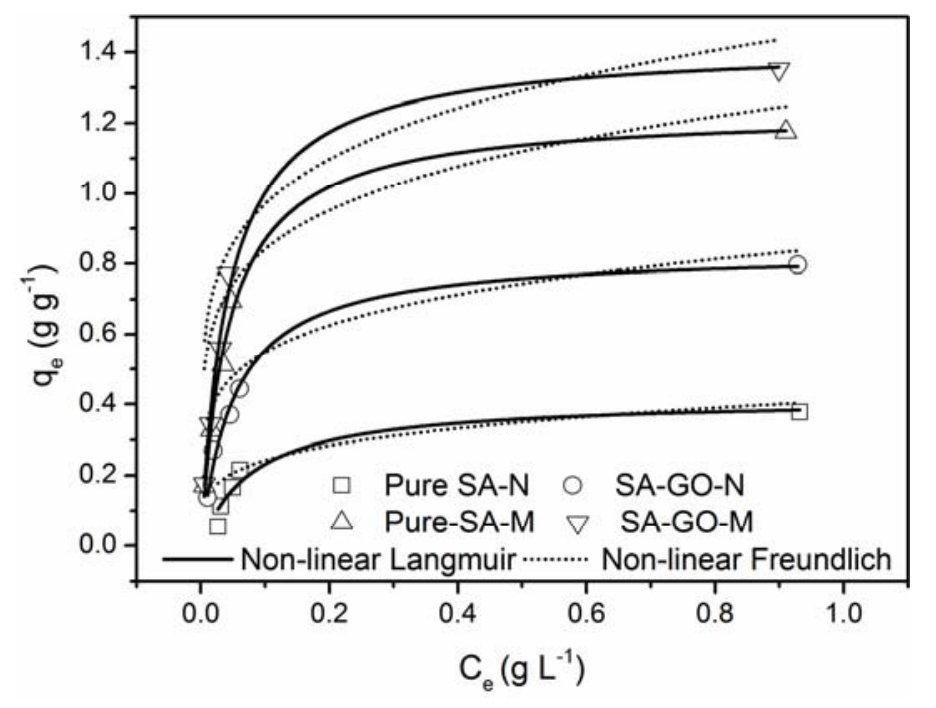


Fig. 6 .
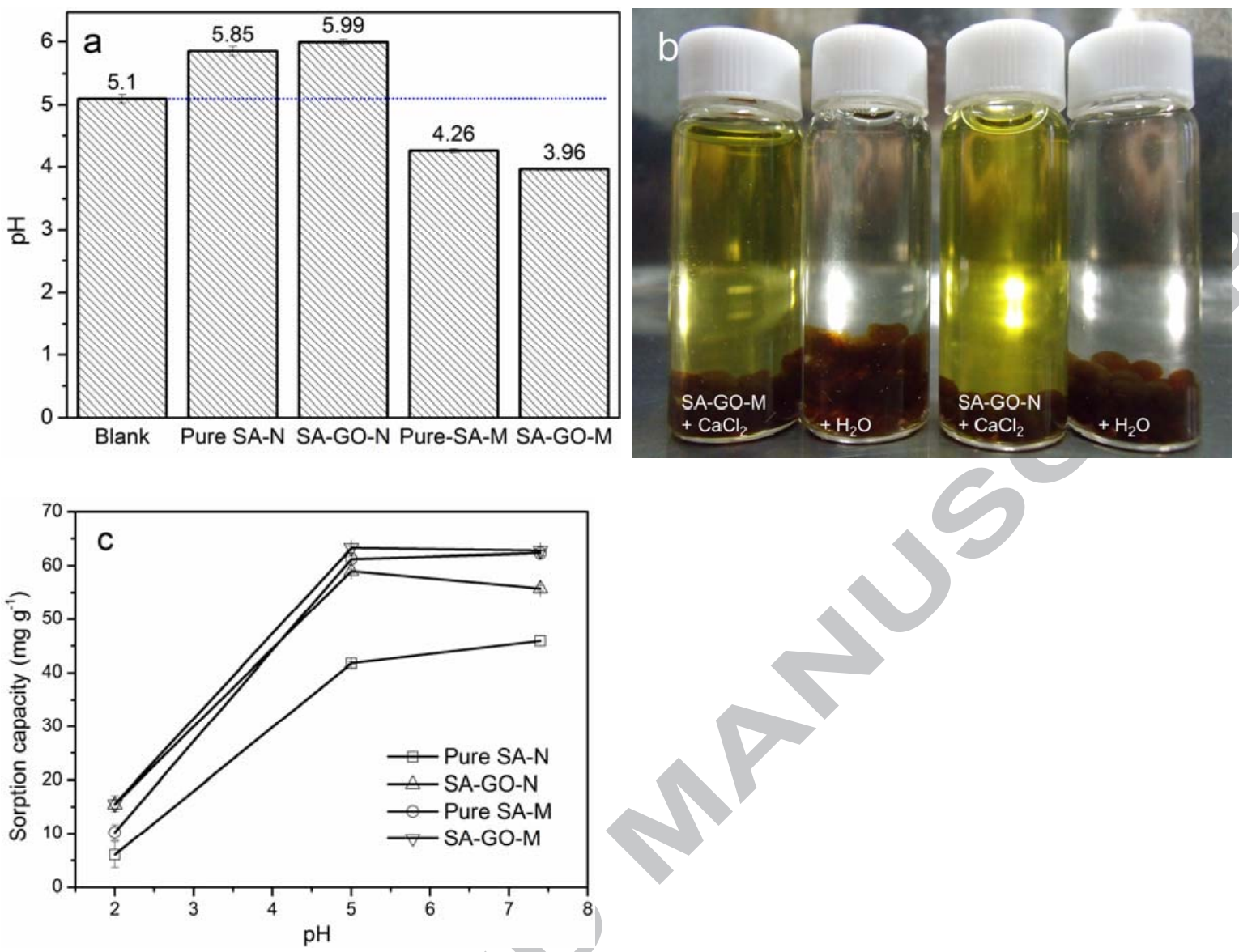


\section{Graphene oxide captured for green use: Influence on the structures of calcium}

\section{alginate and macroporous alginic beads and their application to aqueous removal of acridine orange}

\section{Ling Sun*, Bunshi Fugetsu}

Division of Frontier Research, Research Department, Creative Research Institution, Hokkaido University,

Sapporo 001-0021, Japan

Graduate School of Environmental Science, Hokkaido University, Sapporo 060-0810, Japan

${ }^{*}$ Corresponding author. Telephone/fax: +81-11-706-9235. E-mail: captainsun@ees.hokudai.ac.jp

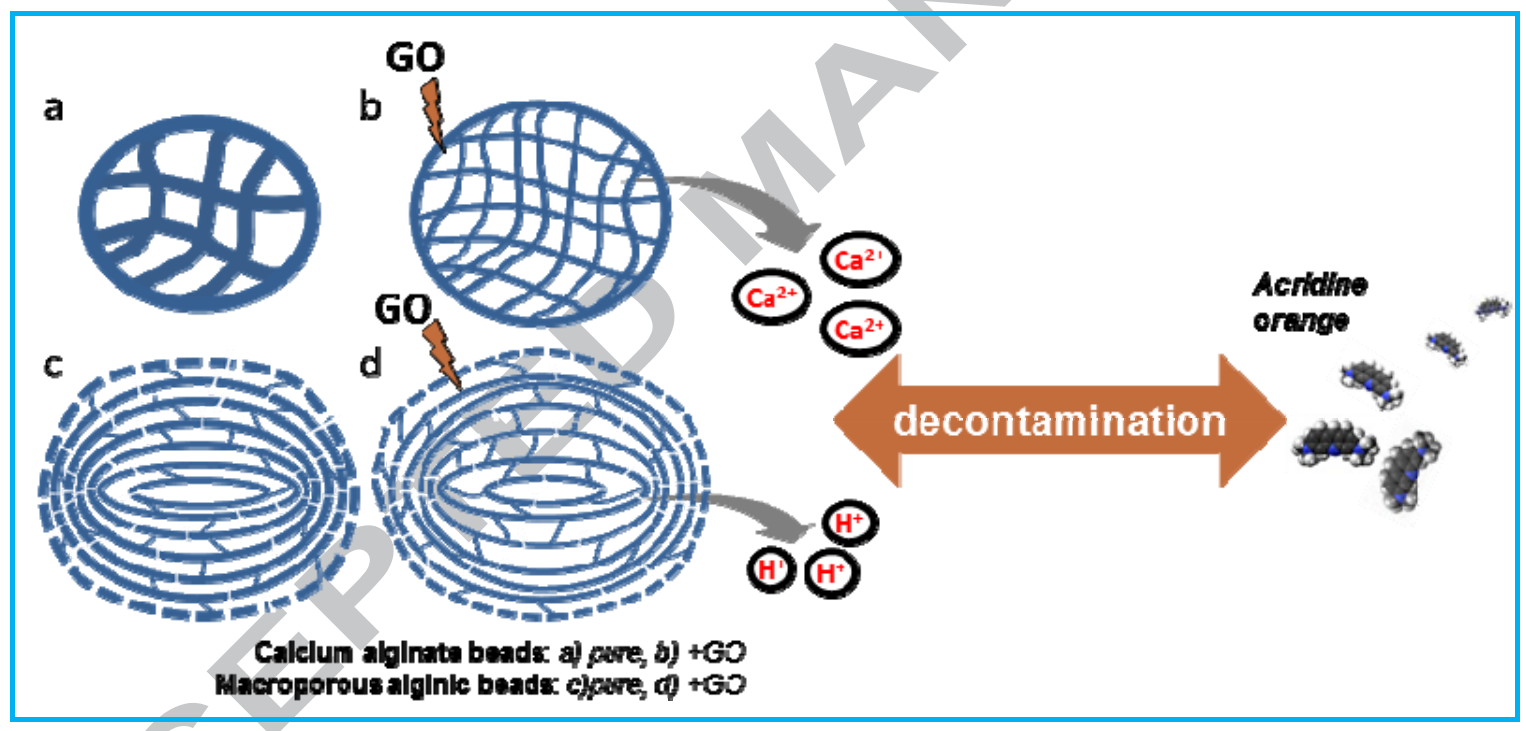




\section{Highlights}

$>$ GO was well encapsulated inside alginate-based matrix as hybrid adsorbents for green use.

$>$ Alginate matrix became porous with the addition of GO.

$>$ Encapsulated GO demonstrated to have enhanced performance towards the dye removal as an example.

$>$ GO played dominantly in adsorption under highly acidic condition. 